\title{
A PRÁtica PEDAGógICA NO USO DE METODOLOGIAS TECNOLÓGICAS ASSISTIVAS PARA A INCLUSÃO DE ALUNOS COM DEFICIÊNCIA VISUAL NA REDE URBANA DE ENSINO NO MUNICÍPIO DE CAMETÁ, NO ANO DE 2019.
}

\author{
Autora:Nidiane Braga de Freitas ${ }^{1}$ \\ CPF: 764.957.442-34
}

\begin{abstract}
Resumo:
Este trabalho buscou descrever a prática pedagógica no uso de metodologias tecnológicas assistivas para a inclusão de alunos com deficiência visual na rede de ensino no Município de Cametá, no ano de 2019. A pesquisa fez uso do método misto, com desenho DITRAS, tendo o enfoque Misto direcionado pelo alcance exploratório seguido do descritivo. A pesquisa teve os seguintes objetivos: Relatar a prática pedagógica no processo de formação dos discentes com deficiência visual no processo ensino e aprendizagerm. Identificar o uso de metodologias tecnológicas assistivas no espaço escolar em termo a formação do discente com deficiência visual. Verificar o processo de inclusão de alunos com deficiência visual na rede de ensino de Cametá. A pesquisa foi direcionada por duas Hipótese investigativas uma afirmativa e outra Nula: A (HIA) Afirmou-se que a prática pedagógica ocorre de maneira satisfatória fazendo uso de metodologias tecnológicas assistivas para promover a qualidade de ensino e a inclusão de alunos com deficiência visual na rede de ensino no Município de Cametá, no ano de 2019. Já a Hipótese Investigativa Nula (HIN).Afirmou-se que a prática pedagógica Não está ocorrendo de forma satisfatória pois o uso de metodologias tecnológicas assistivas, Não se faz presente no espaço educacional comprometendo a qualidade de ensino e a inclusão de alunos com deficiência visual na rede de ensino no Município de Cametá, no ano de 2019.
\end{abstract}

Palavras Chave: Prática pedagógica . metodologias e tecnologicas assistivas. Inclusão de alunos com deficiência visual.

1 Graduada em Pedagogia pela Universidade Federal do Pará (UFPA). Graduada em letraslíngua portuguesa pela Universidade Federal do Pará (UFPA) -PARFOR. Pós-Graduada em Educação Especial e Educação Inclusiva pela Faculdade Internacional de Curitiba (FACINTER), Pós-Graduada em Educação especial com Ênfase em Deficiência Visual pela Faculdade Universidade Católica Dom Bosco (UCDB). Mestranda em Ciência da Educação pela Facultad Interamericana de Ciências Sociales. E-mail: nidianebfreitas@ gmail.com 


\section{INTRODUÇÃOO}

A educação inclusiva é constituída dentro de um paradigma educacional que é fundamentado dentro de uma concepção de direitos humanos, que busca a igualdade em favor das diversidades das pessoas com deficiência, são inúmeras as dificuldades enfrentadas pelas escolas quando se fala em inclusão, essas dificuldades são confrontadas e por maiorias das vezes a ela criada alternativas para superá-las, fazendo parte de discussões e debates quando o assunto a ser tratado é sobre a diversidade humana e suas diferenças, é necessário todo esse debate, para que possamos entender e compreender ,criar formas de trabalhar sobretudo o processo da inclusão,pois é dentro dessa perspectiva, que o Ministério da Educação/Secretaria de Educação Especial Inclusiva, apresenta a Política Nacional de Educação Especial na Perspectiva da Educação Inclusiva conceituando a Educação Especial e definindo dentro dessa política que visa uma igualdade o AEE (Atendimento Educacional Especializado) aos alunos com deficiência dentro da escola regular, sobre o decreto $\mathrm{n}^{\mathrm{o}} .6 .571 / 1008$.

A investigação pelas situações recorrentes na escola com alunos deficientes visuais inclusos mediante práticas e experiências vividas como profissional nos faz pensar nos outros e nas suas capacidades que podem ser desenvolvidas a partir de situações relevantes, levando em consideração a proposta dentro de uma perspectiva inclusiva, a ansiedade familiar, escolar e a do próprio do aluno, essa pesquisa é relevante para compreensão do processo de inclusão dos alunos com deficiência visual, partindo dessa necessidade de compreender mais a prática pedagógica com o uso das metodologias assistivas e as demais ferramentas tecnológicas com o aluno deficiente visual, sua importância para o processo de ensino aprendizagem e seu cotidiano.

As informações tornam-se necessárias e importantes sobre os meios de ferramentas que se fazem presentes na vida e para vida desses alunos inclusos, para tanto, educadores, pais e sociedade num todo necessitam saber de suas existências para que juntos a essas pessoas com deficiência visual possamos galgar e engajar ações para uma melhor inclusão e nos esclarecermos sobre a deficiência visual, suas capacidades e limitações, ampliando novos horizontes no relacionamento humano, afinal, o professor torna-se um personagem do processo de inclusão escolar , mas ,não é somente ele esse agente, todos devem estar envolvidos e engajados com objetivo de tornar plena e de fato a inclusão, dando apoio e aparatos de materiais e humanos.

A pesquisa foi direcionada precisamente à deficiencia visual, as práticas educativas e as metodologias de acessibilidade assistiva para o processo de educação 
especial/inclusiva, uma vez que, possibilita um olhar compreensivo sobre a inclusão de alunos deficientes visuais no contexto das escolas que foram pesquisadas, mediante abordagens qualitativa e quantitativa que direcionam para uma abordagem mista, que permitirá desenvolver de forma detalhada sobre as etapas realizada, todas as pesquisas realizadas tem como definição um alcance exploratório que antecede as demais pesquisas com alcance descritivos, correlacionais ou explicativos ,o que para SAMPIERI, COLLADO E LUCIO (2013, p. 102)

\begin{abstract}
Os estudos descritivos buscam especificar as propriedades, as caracteristicas e os perfis de pessoas, grupos,comunidades, processos, objetos ou qualquer outro fenomeno que se submete a uma analise. Ou seja, pretendem unicamente medir ou coletar informação de maneira independemente ou conjunto sobre os conceitos ou as variaveis a que se referem, isto é, seu objetivo não é indicar como estas se relacionam .
\end{abstract}

Para SAMPIERI, COLLADO E LUCIO (2013), a meta do pesquisador é descrever fenômenos ,situações,contextos e eventos, tornando-se de grande valia a medida que servem para que o pesquisador consiga definir sua linha de pesquisa e seius componentes que serão necessários para sua construção, para tanto, o alcance dessa pesquisa é descritiva, pois, tem-se como propósito descrever como ocorre A prática pedagógica no uso de metodologias tecnologicas assistivas para a inclusão de alunos com deficiencia visual na rede de ensino no municipio de Cametá, no ano de 2018.

A apresentação desse trabalho se dará em quatro marcos sendo eles:

O I Marco Introdutório: Neste apresenta-se a temática e as variáveis que deram sustentação a investigação, a interrogante central, as perguntas investigativas, a contextualização da problemática, a viabilidade, a limitação, além dos objetivos geral e específicos.

No II Marco Teórico: Apresenta-se a fundamentação teórica, o contexto bibliográfico selecionado para respaldar cada variável, seguido das apresentações dos capítulos e incisos, além de aborda as hipóteses e a identificação das variáveis e seus construtores e a identificação conceitual ou teórica.

O III Marco apresenta-se o Marco Metodológico: Neste está o guia metodológico utilizado para realizar a investigação, dando destaque para o tipo de metodologia escolhida, destacando, o tipo de pesquisa, o enfoque, o alcance, o desenho de investigação, a área o lugar da investigação, a população, a amostra e a amostragem, os instrumentos de coleta de dados, procedimentos metodológicos (como vai proceder, aplicar os instrumentos), e o tratamento dos dados. 


\section{BREVE HISTÓRICO SOBRE A CONDUTA DA SOCIEDADE FRENTE AS DEFICIÊNCIAS}

Esse marco faz uma percurso das legislações que contribuíram para o processo de inclusão no Brasil. A trajetória histórica da deficiência é dotada de detalhes meramente construído aos poucos no decorrer dos anos, sendo que, noções que diziam respeito sobre a deficiência em meados do século XVIII eram ligadas ao misticismo e ocultismo, não havendo ainda bases que pudessem fazer com que o tema em si sobre a deficiência fosse tratado de maneira a ser desenvolvido ou até mesmo compreendido dentro de noções realísticas que pudessem tratar do assunto e até mesmo que pudessem pensar na pessoa deficiente como ser humano e vim a trata-lo como sujeito também construtor de sua história, pois a falta de conhecimento tornavam e tornam as pessoas com deficiência mais marginalizadas e ignoradas.

Para COSTA (2014, p.15), um dos grandes desafios para os educadores nesse século é, com certeza, conseguir integrar os saberes e inserir as novas tecnologias no ambiente interativo da aprendizagem, de forma que essas novas ferramentas sejam potencializadoras e promotoras de saberes interessantes para os aprendizes. De acordo com MAZZOTTA (2011, p.27), inspirados em experiências concretizadas na Europa e Estados Unidos da América do Norte, no século XIX, inicia-se a organização de serviços oficiais e particulares para o atendimento das pessoas com deficiência e a inclusão da "Educação de Deficientes", da "Educação dos Excepcionais" ou da "Educação Especial" a política educacional brasileira vem ocorrer somente no final dos anos 1950 e início da década de 1960 do século XX.

Emílio Filgueira (2016, p.11), em sua obra Teologia da Inclusão comenta sobre os registros na história da humanidade em relação a deficiência desde o Antigo Testamento com personagens bíblicos que nos retratam sobre a deficiência como: Noé, Isaac, Jacó e Moisés até o Novo Testamento com a chegada de Jesus e a preocupação do mesmo para com as pessoas deficientes e excluída. O panorama sobre a trajetória da educação especial nos remete ao sentido de que tão longa foram as transformações ocorridas ao longo de sua história dentro em um cenário a qual suas raízes históricas nos aprofundam um olhar crítico de como essas as pessoas com deficiência eram tratadas em cada período de sua história.

O artigo 205 da Constituição Brasileira dispõe que “ a educação é direito de todos e dever do estado e da família”, mas, acrescenta que ela deve ser assegurada "visando o pleno desenvolvimento da pessoa, seu preparo para exercício da cidadania e 
sua qualificação para o trabalho". Levando em consideração que, para acontecer de fato esse atendimento é necessário que haja um profissional qualificado na sala de recursos para realiza-lo, como nos afirma a Secretaria de Educação Especial do Ministério da Educação:

\footnotetext{
Salas de Recursos Multifuncionais são espaços da escola onde se realiza o Atendimento Educacional Especializado para os alunos com necessidades educacionais especiais, por meio de desenvolvimento de estratégias de aprendizagem centradas em um novo fazer pedagógico que favoreça a construção de conhecimentos pelos alunos, subsidiando-os para que desenvolvam o currículo e participem da vida escolar (MEC,2006).
}

De acordo com a Constituição Federal (1988) Art.205 a educação, direito de todos e dever do estado e da família, será promovida e incentivada como a colaboração da sociedade. Visando o pleno desenvolvimento da pessoa, seu preparo para o exercício da cidadania e sua qualificação para o trabalho.

As pessoas com deficiência antigamente eram completamente separadas das demais pessoas, pois eram entendidas como maldição, sem destino e outras maneiras errôneas, por isso, o convívio social a ela não era atribuído, esse modo de agir com as pessoas com deficiência mudou, ganhou novas maneiras de se posicionar diante do sujeito que apesar de suas limitações é em si uma pessoa capaz de aprender e interagir tal como uma pessoa sem deficiência, Por isso, é preciso que sejam dadas a elas condições necessárias para que estas se desenvolvam.

De acordo com A Lei Brasileira da Inclusão (LBI) ou Estatuto da Pessoa Com Deficiência $\mathrm{n}^{\mathrm{o}}$ 13.146/15, a mesma possui 127 artigos a sociedade agora tende a se preparar para receber a pessoa com deficiência e não mais a pessoa com deficiência terá que se adaptar a sociedade que não está apta a recebê-lo, diante desse processo a LBI passa a ser considerada como um processo de conjunto de leis que visam a inclusão através das medidas de caráter social da pessoa com deficiência.

A educação inclusiva consolidada como direito pela Lei Brasileira de Inclusão tem sido um desafio muito grande para os educadores e demais agentes educacionais. Para compreender mais a educação em si, faz-se necessário compreendermos que a elaboração de um de um currículo inclusivo é urgente, sem desconsiderar as particularidades de cada aluno. Para o Estatuto da Pessoa com Deficiência ou Lei Brasileira de Inclusão, a pessoa com deficiência é aquela que tem impedimento de longo prazo de natureza física, mental, intelectual ou sensorial, o qual, em interação com uma ou mais barreiras, pode obstruir sua participação plena e efetiva na sociedade em 
igualdade de condições com as demais pessoas, para a LBI:

Art. 27. A educação constitui direito da pessoa com deficiência, assegurado sistema educacional inclusivo em todos os níveis e aprendizado ao longo de toda a vida, de forma a alcançar o máximo de desenvolvimento possível de seus talentos e habilidades físicas, sensoriais, intelectuais e sociais, segundo suas características, interesses e necessidades de aprendizagem.

A inclusão é um novo paradigma que deve ser abastecido de informações coerentes e significativas, através de um papel social exercido de transformações ocorridas em espaços sociais e educacionais, na qual alunos possam de fato frequentar a escola com aparatos que viabilizem seu processo de ensino e aprendizado que modifica e amplia o entendimento do real valor e caminhos que levam para a mesma, o que para LIRA (2006, p.30-31):

A Conferência Mundial de Educação Especial, reunida em assembleia entre os dias 7 e 10 de junho de 1994, na cidade de Salamanca (Espanha), reafirma o compromisso de uma educação para todos, reconhecendo a urgência para com as crianças, jovens e adultos, esses considerados merecedores de uma educação especial por estarem fora de faixa etária contemplada pela lei. A Declaração de Salamanca, em 1994, propõe uma escola inclusiva, essencial à dignidade humana e ao desfrute e exercício dos direitos humanos, para que os excluídos da escolaridade possam atingir o máximo de progresso educacional e a integração social. Orienta, ainda, para o desenvolvimento comunitário que deveria vir além das atividades da escola; associação de bairro, de famílias, movimento de jovens e voluntários.

O Brasil se comprometeu internacionalmente e adotou a Política de Educação Especial/ Inclusiva, em fazer com que, todas as pessoas com deficiências venham estudar e compartilhar do mesmo espaço que as pessoas sem deficiência, uma vez, que a inclusão vai além do fato de ser simplesmente lei, ela é uma mudança de estruturas pedagógica, social, apoio, recursos matérias que requer uma mudança de comportamento social perante os desafios de uma prática complementar acessível que exige positividade e condições de acesso permanente para que haja o desenvolvimento e acessibilidade enquanto estrutura de uma educação inclusiva.

De acordo com LBI em seu art. 27

A educação constitui direito da pessoa com deficiência, assegurado o sistema
educacional inclusivo em todos os níveis e aprendizado ao longo de toda a
vida, de forma a alcançar o máximo desenvolvimento possível de seus talentos
e habilidades físicas, sensoriais, intelectuais e sociais, segundo suas
características, interesses e necessidades de aprendizagem.

Atualmente nas escolas, nos locais da sociedade em geral se convive com outros alunos ou pessoas com deficiencia e isso tornou-se comum e importante, mas tudo isso 
veio de grandes lutas para conquistas de direitos estabelecidos que tiveram por meio desta grandes promulgações de leis que viabilizasse e tornasse de fato real o processo de inclusivo.

\section{METODOLOGIAS TECNOLÓGICAS ASSISTIVAS NO ESPAÇO ESCOLAR EM TERMO A FORMAÇÃO DO DISCENTE COM DEFICIÊNCIA VISUAL.}

No segundo capítulo é feita a descrição das metodologias assistivas no espaço escolar na formação do educando deficiente visual, bem como as tecnologias assistivas para inclusão desse aluno e as principais tecnologias que podem ser usadas como auxilio no espaço escolar para o processo de ensino aprendizagem como por exemplo o braille. As informações tornam-se necessárias e importantes sobre os meios e ferramentas que se fazem presentes na vida e para vida desses alunos inclusos, para tanto, educadores, pais e sociedade como um todo necessitam saber de suas existências para que, juntos a essas pessoas com deficiência visual possamos galgar e engajar ações para uma melhor inclusão e nos esclarecermos sobre a deficiência visual, suas capacidades e limitações, ampliando novos horizontes no relacionamento humano, onde todos os agentes possam se tornar personagens envolvidos e engajados nesse processo e não somente o professor para gerenciar o apoio e aparatos de materiais e humanos sempre que necessário. Para GRANDI $(2010, \mathrm{p} .41)$

os avanços da tecnologia da informação dão grandes saltos a cada dia, o conhecimento da informática é indispensável para a inclusão da pessoa com deficiência visual no ensino, no trabalho, no lazer e também, podemos dizer, na melhoria de sua qualidade de vida e da auto estima.

VYGOTSKI (1989, p.79), nos aponta dois tipos de pessoas cegas, a primeira pessoa cega para o autor seria as que negam as diferenças entre videntes e cegos e a segunda pessoa seriam aquelas que acreditam numa personalidade própria, particular para os cegos, pois para ele:

Seria um erro ingênuo da pessoa vidente supor que encontraremos na psique do cego a cegueira ou a sombra psíquica, a projeção, a representação; em sua psique não há nada, salvo as tendências à superação da cegueira, a tendência à supercompensação e o intento por conquistar uma posição social.

Entender a educação inclusiva como um processo de direito de todos e para 
todos é a primeira iniciativa que devemos ter para transformar uma sociedade que durante décadas vem se mantendo excludente e consequentemente geradora de desigualdades sociais, para isso precisamos compreender e aceitar as diferenças que perpassam sobre cada sujeito, pois a educação inclusiva não é meramente um fator novo e vem sendo historicamente conquistada por meio de lutas, por isso, é necessário e urgente um currículo também inclusivo, que atenda a todos os alunos e valorize as suas especificidades.

Por isso, é necessário chamar atenção à um compromisso que venha cercar a todos os envolvidos no processo de inclusão desde o sistema escolar, familiar , comunidade e escola, na qual onde todos sintam-se preocupados com a qualidade de uma educação gratuita e pública, pois a pessoa cega também se constitui nas interações da vida social, pois para VYGOTSKY,2009, P. 82 “a concepção de homem não é a de um ser passivo, fruto das relações, mas a de um ser ativo, que age sobre o mundo através das relações sociais".

VYGOTSKY, sempre em seus estudos evidenciou a importancia do papel do outro como mediador da cultura que é repassada dentro das relações estabelecidas, nas quais passam a possibilitar todo um desenvolvimento mediado pelo outro para o significado dos objetos e experiencias vividas e repassada às crianças.

\section{O PROCESSO DE INCLUSÃO DE ALUNOS COM DEFICIÊNCIA VISUAL}

O capítulo três, por sua vez, apresenta uma descrição sobre o processo de inclusão dos alunos deficientes visuais, as suas dificuldades e a importância da família para que este processo ocorra. Conhecer o caminho que percorreu a educação especial/inclusiva faz-se necessário para o real entendimento da política pública em detrimento às pessoas com deficiencia na sociedade, olhar para os projetos e leis trabalhadas a favor do aluno defficiente visual e seu desenvolvimento, as dificuldades mediante as limitações e suas habilidades, divulgando assim, a importancia do sistema braille e demais ferramentas tecnologicas assistivas relevantes aos deficientes visuais .

Refletir sobre a função social da escola e da familia como um todo é fundamental, embora, atualmente se falando muito sobre o assunto, este ainda é para muitos um tema novo, portanto, a busca de descrever como estão sendo trabalhadas as práticas educativas e as tecnologias assistivas dentro das dinâmicas interativas nas escolas com os alunos deficientes visuais na rede urbana municipal de ensino do município de Cametá, esse reconhecimento viabiliza como todo o processo de ensino e aprendizagem ocorre e como 
estas ferramentas permitem ao educador e educando trabalhar diante das limitações para o desenvolvimento e potencial diante das limitações sensoriais desses educandos. Pois a compreensão do processo inclusivo é algo pertinente para que possamos entender tais caminhos e a garantia de condições de acesso e de aprendizagem dentro do espaço escolar a estes aluno.

EMÍLIO FIGUEIRA (2017, p.62), nos fala da importância de que precisamos fazer a mudança de consciência de cada um de nós, a começar pela pessoa com deficiência, pois esta precisa saber de suas situações e limites que possui para saber como e para que agir, para que essa aconteça também na sociedade como um todo, pois para ele o indivíduo conscientizado não fica indiferente e também não desanima diante dos obstáculos que surgem nas situações da vida, sendo que para ele "a participação é um compromisso de vida, exigida como um direito e procurada como uma necessidade".

Como na escola o aprendizado é um proceso pedagógico privilegiado, o professor tem o papel explicito de interferir na zona de desenvolvimento proximal dos alunos, provocando avanços no educando, sendo que para VYGOSTKY "o bom ensino é aquele que se adianta ao desenvolvimento", por isso a interação social é fundamental na construção do ser humano e o processo de das práticas pedagógicas como fator que nortea a aprendizagem acaba se relacionando também dentro do fator de dimensão social como sendo um processo de desenvolvimneto ao longo da vida do aluno.

A pesquisa leva em consideração uma abordagem Mista em torno do tema proposto sobre a prática pedagógica no uso de metodologias tecnológicas Assistivas para a inclusão de alunos com deficiência visual na rede de ensino no Município de Cametá, no ano de 2019, nela deu-se o uso do estudo de natureza mista, utilizada para se chegar a essa dinâmica como processo sistemáticos, críticos e empíricos, como toda pesquisa requer seriedade, veracidade e busca de solução, SAMPIERI, COLLADO E LUCIO (2013,p.30 e 33) determina que a pesquisa mista torna-se fundamental no campo da educação, pois utiliza tanto a pesquisa quantitativa quanto a qualitativa para evidenciar a investigação de um único fenômeno, ou objeto de investigação de alcance exploratório visando à descoberta, o achado, a elucidação de fenômenos ou a explicação daqueles que não eram aceitos apesar de evidentes.

$\mathrm{O}$ alcance exploratório permite uma maior familiaridade entre o pesquisador e o tema pesquisado, direcionada pelo Desenho Transformador Sequencial (DITRAS), que tem como objetivo principal colaborar com a perspectiva teórica do pesquisador que passa a considerar as opiniões dos participantes e grupos pesquisados utilizando duas etapas para o processo de realização das análises dos dados, a pesquisa será realizada na cidade 
de Cametá, Município do Estado do Pará, tendo como população pesquisada a educação especial inclusiva, precisamente o público de alunos com Deficiência Visual (DV) nas Salas de Recursos (SRM) frequentando o atendimento educacional especializado (AEE), em dois lócus da investigação, sendo um Centro de Inclusão Educacional de Cametá CIEC e a uma E.M.M.F. Raimunda da Silva Barros.

\section{CONSIDERAÇÕES FINAIS}

A finalização deste estudo sobre a prática pedagógica no uso de metodologias tecnológicas assistivas para a inclusão de alunos com deficiência visual na rede urbana de ensino no município de cametá, no ano de 2019, mostrou que uma das compreensões sobre a política de educação especial na perspectiva de educação inclusiva é a de que as políticas públicas são essenciais para a concretização de ações inclusivas que possibilitem ao professor uma formação sólida a respeito da educação inclusiva nas suas práticas pedagógicas levando-o a fazer uso dos recursos de tecnologias assistivas no processo de ensino e aprendizagem do aluno deficiente visual.

O processo de formação em fase as tecnologias assistivas nas práticas pedagógica do professor deve ser uma maneira de garantir uma formação inicial e continuada para se desenvover uma prática inclusiva que permita ao professor usar as tecnologias para fins educativos, mas compreendendo, ao mesmo tempo, os sentidos e as finalidades da tecnologia na educação e na formação humana dos sujeitos. Com relação a esse contexto da política pública de educação inclusiva, foi constatada uma falha, que vem repercutindo não somente nas escolas pesquisadas, mas de uma maneira municipal e chamado atenção seu processo de implantação, as especificidades e acessibilidades diante do processo de ensino aprendizagem do aluno com deficiente visual e como maneira de não refletir de forma negativa precisa ser trabalhada de maneira contínua na prática do professor.

Nesse sentido, mais ações são necessárias para que as políticas públicas educacionais inclusivas se materializem, de fato, na sociedade, na escola, possibilitando aos sujeitos reconhecer sua real transformação social e cidadã. Todavia, essas ações devem ser reais, no sentido de possibilitar que as classes sociais menos favorecidas e as pessoas com deficiência não sejam excluídas de todo esse processo educacional.

Ao direcionar a pesquisa para a prática pedagógica no uso de metodologias tecnológicas assistivas para a inclusão de alunos com deficiência visual na rede urbana de ensino no município de cametá, identificou-se que as formações têm sido executadas 
de diversas maneiras na tentativa de expandir seu trabalho na rede de ensino municipal, a partir de diversos programas de formação de professores, minicursos e outros como maneira de assegurar o processo de educação inclusiva.

Ademais, é existente também um problema relacionado ao acompanhamento e ao assessoramento das formações e ações atuante sobre continuada aos professores da rede pública de ensino, em relação ao uso dos recursos tecnológicos na educação. Todavia, esse processo de formação deve ser elaborado e implementado por profissionais capacitados, para a efetivação de um processo de formação continuada de professores a partir da realidade educacional do município de Cametá.

Os resultados desta pesquisa revelam a necessidade de aprofundamento de estudos e reflexões sobre o tema aqui abordado, uma vez que a formação de professores em informática educativa precisa ser melhor tratada e efetivada nas secretarias de educação dos estados e municípios, sobretudo nos dias atuais em que a presença das tecnologias da informação e comunicação já é uma realidade na educação.Quando falamos de educação inclusiva, devemos falar também de acessibilidade, não devemos esquecer que para trabalhar a inclusão, devemos perpassar em todos os âmbitos da vida em sociedade, pois, a educação inclusiva precisa ser pensada em todos os âmbitos não somente escolar mais em todos os âmbitos sociais.

E a acessibilidade é de fundamental importância para todas as pessoas com deficiência, sendo que, a elas é garantindo por meio da acessibilidade uma melhor qualidade de vida. Dessa maneira promover o acesso as pessoas com deficiência visual na escola, é garantir a eles possibilidades de progressão e autonomia na vida como forma destes superarem barreiras encontradas em suas vidas. A escola deve buscar estratégias e recursos para que a promoção do aluno com deficiência aconteça e que este seja realmente incluído, para isso a Tecnologia Assistiva é uma maneira do aluno ser incluído de forma positiva, assim:

Portanto, para que todo esse processo aconteça de fato, é necessário que todos tenham uma postura certa de suas metas, assim como o professor, com uma postura pedagógica na criação de meios e estratégias de ensino bem como, em aparatos didáticos que garantam o processo de ensino e a aprendizagem do educando com deficiência visual. A educação é um fator de necessidade humana, construída ao longo de nossas vidas, promove a busca para melhores condições do ser humano viver em sociedade como um sujeito que interage e se socializa sobre as questões diárias, assim a educação é importante e essencial para o indivíduo em suas mudanças e de fundamental estímulo para que tais mudanças ocorram de forma organizada, planejada e sobretudo positiva. Assim vale 
ressaltar que vários são os fatores que favorecem nesse processo de ensino aprendizagem e ajudam a vincular mecanismos em favor de métodos de transformação de sujeitos críticos e reflexivos.

Ensinar exige além de dedicação, conhecimentos e, sobretudo formação, para que isso ocorra se faz necessário compreender os papeis e diante deles trabalhar com objetivos a ser alcançado, trabalhar a inclusão de alunos com deficiência não é somente uma questão pedagógica do professor em sala de aula como podemos constatar, mais sim, da escola como um todo, gerando como ponto de partida o processo de formação como cidadão, bem como, em seguida favorecendo métodos para que sejam viáveis em torno do que tange o processo de ensino e aprendizagem. Sabemos que ao longo da trajetória humana, o homem evoluiu e junto a essa evolução está à tecnologia como fruto desse desenvolvimento, hoje, vivemos com meios tecnológicos que nos favorecem e precisam estar presente no processo de ensino aprendizagem de nossos alunos, pois estes meios se tornam ferramentas essenciais para todo desenvolvimento.

Por isso, é importante que seja usado o Sistema Braille no processo de ensino e aprendizagem de escrita e leitura tátil, para alunos deficientes visuais e os programas de voz que devem fazer parte do contexto dos nossos alunos e que nós professores precisamos estar em constante formação, nesse sentido, trabalhar o Sistema Braille e os softwares programas de voz, e todas as metodologias assistivas com os alunos deficientes visuais é de grande importância, pois favorece ao aluno e ao educador em suas atividades não somente em sala de aula, mas em suas próprias atividades diárias, pois as diversas maneiras estão e se fazem presentes em nossas vidas.

É de suma importância que estejamos mais atentos e flexíveis às mudanças que ocorrem, porque elas fazem parte do contexto de vidas de nossos alunos e estes convivem constantemente com tais mudanças e precisam delas para desenvolver-se plenamente como sujeito ativo e participativo, pois a educação de uma criança com deficiência visual pode ser organizada como a educação de qualquer outra criança.

\section{REFERÊNCIAS}

ANTUNES, Celso, 1937.Vygotsky, quem diria?!: em minha sala de aula: fascículo 12/8.ed.petropolis, RJ: vozes,2011.

BRASIL. Ministério da Educação. Secretaria de Educação Especial. Marcos Políticos-legais da Educação Especial Inclusiva/Secretaria Educação Especial.- Brasília:2010.

CUNHA, Antônio Eugênio. Práticas pedagógicas para a inclusão e diversidade.6.ed.-rio de janeiro: wak editora,2016. 
FERNANDES, Sueli. Fundamentos para educação especial. Curitiba: Ibpex,2006.

FIGUEIRA, Emilio. Teologia da inclusão- a trajetória das pessoas com deficiência na história do cristianismo. São Paulo.2015.

GOMES FILHO, Antônio costa; STORA, Ana Paula; AMARAL, Keli rodrigues do; NASCIMENTO, Ana Lídia Cardoso do (Org.). Educação inclusiva no RENAFOR: nova formação docente para a reconfiguração da prática pedagógica. Belém-Universidade Federal Rural da Amazonia, 2014. ALBUQUERQUE, Raphaela Duarte Lopes de; BRASIL, Silvany Ellen Risuenho (orgs). Belem;L\&A editora, 2015.

GRANDI, Antônio Carlos. Informática e Deficiência Visual: uma relação possível? 1.ed.- são Paulo: Fundação Dorina Nowill para cegos, 2010.

LAKATOS, Eva Maria; MARCONI, Marina de Andrade. Metodologia Científica. 7.ed.- São Paulo: Atlas, 2007.

MAIOLA, Carolina dos Santos. Deficiência visual. Indaial: Editora UNIASSELVI, 2009.

MANTOAN, Maria Teresa Egler (organizadora). O Desafio das Diferenças nas Escolas.5.ed.Petrólis, RJ:Vozes,2013.

MANTOAN, Maria Teresa Egler. O desafio das diferenças nas escolas.4.ed.- Petrópolis, RJ: Vozes, 2011.

MARCONDES, Maria Inês; Apoluceno Ivanilde de. Abordagens teóricas e construções metodológicas na pesquisa em educação. Editora filiada ABEU Associação Brasileira das editoras Universitarias.2011

MARCONDES, Maria Inês; TEIXEIRA, Elizabeth; OLIVEIRA, Ivanilde Apoluceno de. Metodologias e técnicas de pesquisa em educação. Belém: EDUEPA,2010.

MARTINEZ, Albertina Mitjáns; TACCA, Maria Carmen Villela Rosa. Possibilidade de aprendizagem: ações pedagógicas para alunos com dificuldade e deficiência. Campinas, SP: Editora Alínea, 2011.

MARTINS, Joseth Antônia Oliveira Jardim. A educação especial no contexto socioeconômico brasileiro. Curitiba: IBPEX,2003.

MAZZOTTA, Marcos J.S. Educação Especial no Brasil: História e políticas públicas- 6.ed.são Paulo: cortez,2011.

LIRA, Bruno carneiro.Práticas Pedagógicas para o Século XXI: a sociointeração digital e o humanismo ético.Petrópolis, RJ : Vozes,2016.

OLIVEIRA, Maria Marly de. Como fazer pesquisa qualitativa.4.ed.- Petrópolis, RJ: Vozes,2012.

VELOSO, Renato. Tecnologias da informação e da comunicação: desafios e perspectivas. São Paulo: saraiva, 2011.

ZAPPAROLI, Kelem. Estratégias da criança com deficiência. 2.ed. - rio de janeiro: wak editora, 2014. 